\title{
Development of New Bexarotene-loaded Mesoporous Silica Systems for Topical Pharmaceutical Formulations
}

\author{
Aurelia Vasile, ${ }^{1}$ Maria Ignat, ${ }^{1,2, *}$ Mirela Fernanda Zaltariov, ${ }^{2}$ \\ Liviu Sacarescu, ${ }^{2}$ Iulian Stoleriu, ${ }^{4}$ Dan Draganescu, ${ }^{5}$ Mihai Dumitras ${ }^{1}$ \\ and Lacramioara Ochiuz ${ }^{3}$
}

\author{
${ }^{1}$ Department of Chemistry, “Alexandru Ioan Cuza” University from Iasi, 11 Carol I Bvd., 700506, Iasi, Romania \\ ${ }^{2}$ Institute of Macromolecular Chemistry "Petru Poni” Iasi, Aleea Grigore Ghica Voda, nr. 41 A 700487 Iasi, Romania \\ ${ }^{3}$ Faculty of Pharmacy, "Gr.T. Popa” University of Medicine and Pharmacy from Iasi, 16 Universitatii Street, \\ 700115, Iasi, Romania \\ ${ }^{4}$ Faculty of Mathematics, "Alexandru I. Cuza” University, 11 Bvd. Carol I, Iaşi, 700506, România \\ ${ }^{5}$ APIS Laboratories LTD, street Prof. Petru Olteanu 2F, Iasi \\ *Corresponding author: E-mail: maria.ignat@uaic.ro,ignat.maria@icmpp.ro
}

Received: 18-06-2017

\begin{abstract}
The present study reports the first time use of MCM-41 mesoporous silica as highly efficient carrier for bexarotene - an antineoplastic agent specific for cutaneous T-cell lymphoma treatment. Bexarotene is highly toxic and poor-water soluble, having low bioavailability in the conventional pharmaceutical forms. Comparative uptake of bexarotene on amino-functionalized silica host at various functionalization degrees is discussed in details taking into account all structural features, of matrix as well as properties of the drug molecules. The obtained results proved a successful bexarotene loading on amino-functionalized MCM-41 silica. The bexarotene molecules are adsorbed on the active centers in non-crystalline state proving the major role of the silica amino-functionalization for the drug solubility and bioavailability enhancing. In vitro dissolution tests showed a prolonged release of bexarotene during $12 \mathrm{~h}$, reaching $50 \%$ release of loaded active molecules. The prolonged release has been demonstrated to be a result of the presence of aminopropyl groups on the silica pore walls.
\end{abstract}

Keywords: Aminofunctionalized mesoporous silica, carrier bexarotene, release

\section{Introduction}

Generally, if a drug provides high therapeutic efficacy, diminished side effects and does not induce unacceptable toxicity levels, it is used in disease treatment. These requirements can be accomplished, in the case of the existing medication, by using new administration possibility as transport and controlled delivery systems. Nowadays, due to their advantages as the ability to incorporate lipophilic and hydrophilic substances, low toxicity, extended persistence into the blood stream, the gradual and controlled drug release and safe administration (produces no local inflammatory reaction), as well as the allowance to be used in adequate doses and to target the drug, controlled Drug
Delivery Systems (DDS) are increasingly preferred compare to conventional administration methods. ${ }^{1-4}$

Since 2001, when M. Vallet-Regi et al. ${ }^{5}$ made known the first results, due to their biocompatibility and relative easily adjustable physicochemical properties, the use of mesoporous silica materials for the development of such controlled drug delivery systems, caught the attention of many researchers. Among them, MCM-41 type mesoporous silica, has found to have remarkable applications in DDS preparation (to be used for treatment of various diseases: inflammatory, cancer, diabetes, neurological disorders, even as carriers in gene therapy or biosensors for diagnosis), as well to have a huge potential for diversification of such systems. The key properties of this versatile mate- 
rial are due to the ordered structure at meso-scale level (ordered pores ranging in size from 2 to $10 \mathrm{~nm}$ ), and surface chemistry that allows the insertion in a controlled manner of new functionalities and thus potential applications. The high specific surface area $\left(>1000 \mathrm{~m}^{2} / \mathrm{g}\right)$, large pore volume $\left(\sim 1.0-2.0 \mathrm{~cm}^{3} / \mathrm{g}\right)$, and consequently the high sorption/hosting capacity for bioactive molecules, the relative simple, inexpensive, environmentally friendly and controllable synthesis procedure, the biocompatibility and lack of toxicity, explain the particular interest reflected in a large number of publications worldwide. Thus, pure or modified MCM-41 mesoporous silica was used as carrier for various types of drugs, such as ibuprofen, ${ }^{6}$ aspirin, ${ }^{7,8}$ naproxen, ${ }^{9}$ doxorubicin, ${ }^{10}$ captopril, ${ }^{11}$ erythromycin, ${ }^{12}$ celecoxib, ${ }^{13}$ econazole nitrate, ${ }^{14}$ famotidine,${ }^{15}$ mesalazine, ${ }^{16}$ tetracycline, ${ }^{17}$ alendronate, ${ }^{18,19}$ curcumin, ${ }^{20,21}$ folic acid, ${ }^{22}$ etc. More information can be found in exhaustive investigation on drug release from silica-based ordered mesoporous materials, reported by Maria Vallet-Regi et. al. in $2015 .^{23}$

Also, are known core-shell nanoparticles consisting of magnetic iron oxide cores and MCM-41 mesoporous silica shells with controllable magnetization for nanoconfinement of antineoplastic agents. ${ }^{24,25}$ Such systems may be used to transport drugs to the diseased organ of a patient, when an external magnetic field is applied.

The controlled functionalization of the MCM-41 silica pore surface (internal surface) results in fine tuning of the host-guest chemistry, an essential factor for modified drug delivery systems (MDDSs) preparation. Only for particles smaller than $100 \mathrm{~nm}$ with a high specific surface area, the selective functionalization of the external and internal surface is relevant. Both adsorption of the bioactive agent (physisorption) and its release (diffusion) are influenced by the hydrothermal stability, pore size and structure, functionalization (the density of the organic fragments attached to the surface), surface polarity, the properties of the bioactive agent, and the loading method. Physical interaction forces between bioactive molecules and the pore walls and the diffusion through the pores are fully controllable through internal surface functionalization.

Generally, the surface modification of MCM-41 silica by functionalization can be accomplished through: (i) the co-condensation process during synthesis procedure, (ii) by post-synthesis grafting process, and (iii) surfactant displacement. Although, by involving the co-condensation process, the distribution of the functional groups is uniform, the removal of the structuring agent is difficult, laborious and there is a risk to leave in the structure undesirable fragments of the surfactant/co-surfactant molecules for the biomedical applications. For this reason, most often, the grafting of the organic fragments on the calcined MCM-41 silica surface by post-synthesis treatments is preferred.

Bexarotene (4-(1-(5,6,7,8-tetrahydro-3,5,5,8,8-pentamethyl-2-naphtalenyl) ethenyl) benzoic acid) (BXT) is an antineoplastic specific agent for treatment of cutaneous T-cell lymphoma (CTCL). However, poor water solubility and low dissolution rate significantly limit the bioavailability of BXT. In topical applications, bexarotene usually induces irritant dermatitis, requiring a careful monitoring and a gradual dose increase to provide a correct therapeutic ratio. ${ }^{26}$

In the present study, is proposed a way to overcome these disadvantages, namely the preparation of BXT-based modified drug delivery systems characterized by and enhanced solubility, therefore and bioavailability, and a prolonged release in order to develop new dosage forms for treatment of cutaneous T-cell lymphoma.

Mesoporous silica, MCM-41 type, used for the preparation of such systems have been synthesized by an innovative method (sonochemical), modified through amino-functionalization and loaded with the specific drug. The obtained MDDSs systems were subjected to in vitro testing in order to establish the release profile of the drug.

\section{Experimental Section}

\section{1. Materials}

Test experiment was performed using the following reagents: tetraethyl orthosilicate (TEOS, 98\%, Merck) as the silicon source; cetyltrimethylammonium bromide (CTAB, 99\%, Merck) as the cationic surfactant structuring agent; 3-aminopropyltriethoxysilane (APTES, 99\%, Sigma-Aldrich) as a functionalizing agent; bexarotene (BXT, 98\% Zhejlang Sanmen Hengkang China Pharmaceutical Co. Ltd.) as an antineoplastic agent, absolute ethanol (99.3\% Chemical Company, $\mathrm{RO})$; aqueous ammonia $\left(\mathrm{NH}_{3}\right.$ min.25\% Chemical Company, RO), hydrochloric acid (35$38 \%$, Chemical Company, RO), toluene (98\%, P. A. Chemical Company, RO). All reagents have been used without further purification. Deionized water was obtained with water purification Elga PureLab system. Reagents as trifluoroacetic acid (TFA, Merck, Germany); acetonitrile (chromatographic purity, Merck, Germany); glacial acetic acid (Merck, Germany); potassium phosphate (Sigma Aldrich, Germany), ethyl alcohol (pro analysis, Sigma Aldrich, Germany) double distilled water: Millipore, conductivity $-0.01 \mu \mathrm{S} / \mathrm{cm}$ were used for HPLC analysis.

\section{2. Synthesis Procedure}

The synthesis of MCM-41 mesoporous silica was carried out in alkaline conditions by ultrasonication process using an ultrasonic generator SONICS VIBRA Cell TM Model CV 33 operating in a pulse mode ( $3 / 1 \mathrm{~s}$ on/off cycle) for 2 hours, and a constant temperature of $25^{\circ} \mathrm{C}$. The reaction mixture had the following molar composition:

1TEOS: 0.3CTAB: $95 \mathrm{EtOH}: 15 \mathrm{NH}_{3}: 246 \mathrm{H}_{2} 0$. 
Initially, the well-known amount of CTAB was dissolved in a corresponding calculated volume of distilled water, until a clear solution was obtained. Then, to the $\mathrm{CTAB}$ solution ethanol is added and the obtained mixture was subjected to an ultrasound irradiation for $5 \mathrm{~min}$. Further, the ultrasonication is continued for another $15 \mathrm{~min}$, when aqueous ammonia was added to the reaction mixture. Finally, during ultrasonication, in the first $20 \mathrm{~min}$ of working time the TEOS was added drop wise to the reaction mixture, and left for maturation for $2 \mathrm{~h}$.

The obtained product was centrifuged, washed several times with distilled water until a negative test for the presence of bromine have been reached, and then dried in air at room temperature. To create porosity, the structure directing agent was removed by calcination at $550{ }^{\circ} \mathrm{C}$ for $6 \mathrm{~h}$ with a rate of temperature increase of $1 \% \mathrm{~min}$. The resulted product was denoted as $\mathrm{M}$.

\section{3. Amino-functionalization of Mesoporous Silica}

Although at the start point of preliminary tests for the immobilization of BXT bioactive agent on the M sample have shown retention of large amounts, BXT molecules diffuse outward due to the weak electrostatic and steric influences of the silicate framework.

The obtained results justify the necessity of the controlled modification of MCM-41 mesoporous silica surface through bonding some functional groups that increase physical interaction with BXT molecules. For this purpose, modification of $\mathrm{M}$ sample with 3-aminopropyltrietoxisilane was performed. Three different samples were obtained with different functionalization degree expressed in weight percentage of aminopropyl groups. In grafting process, the isolated and vicinal silanol groups act as efficient anchoring points for further functionalization by elimination reactions. The grafting process occurred in anhydrous conditions which are essential for prevention organosilane reaction with water. Before functionalization, samples were dried at $150^{\circ} \mathrm{C}$ for $5 \mathrm{~h}$, to remove the physically adsorbed water.

The typical grafting experiment has been carried out by contacting $1 \mathrm{~g}$ of $\mathrm{M}$ sample with $30 \mathrm{~mL}$ of anhydrous toluene, followed by magnetic stirring (during $30 \mathrm{~min}$ ), drop wise adding of a specified quantity of APTES (the APTES amount was varied between 2.25 and $4.33 \mathrm{mmol}$ ), afterward the mixture was refluxed at $110^{\circ} \mathrm{C}$, for $8 \mathrm{~h}$.

The final products were separated by centrifugation, washed with ethanol, and let to dry at room temperature. The obtained samples were labeled as $\mathrm{MG}_{\mathrm{x}}(\mathrm{x}$ - functionalization degree: $1 ; 2 ; 3)$.

\section{4. Preparation of Modified Drug Delivery Systems (MDDS)}

The loading process of guest molecules on the mesoporous silica is based on the physical adsorption from solution. Because BXT in almost water insoluble, anhydrous ethanol have been chosen as solvent. In order to determine the required time for reaching equilibrium, the kinetics of the adsorption process have been studied. The kinetic study was carried out using a $1 \mathrm{mg} / \mathrm{mL}$ BXT solution, at native $\mathrm{pH}$ of 4.5 under magnetic stirring at room temperature $\left(20 \pm 0.5{ }^{\circ} \mathrm{C}\right)$ under light-sealed conditions and dark. In order to avoid the experimental errors induced by withdrawing aliquots of solution, each point of the study was evaluated in separate solutions. This way, at all times we ensured $100 \mathrm{mg}$ of $\mathrm{MG}_{\mathrm{x}}$ matrix in contact with $50 \mathrm{ml}$ of drug solution. The adsorbed amount was determined indirectly by measuring the solution concentration before and after adsorption. The prepared MDDSs were noted as BXT@MG, BXT@MG 2 and BXT@MG .

\section{5. Study of the in vitro Dissolution of BXT from Prepared MDDSs}

Taking into account the poor solubility of BXT in water or phosphate buffer solution, ${ }^{27,28}$ the in vitro dissolution tests of the three systems (BXT@MG, BXT@MG BXT@ $\mathrm{MG}_{3}$ ) were carried out using ethyl alcohol:phosphate buffer solution (ratio of 3:1) as dissolution media. The test was performed on a SR8 Plus Series (AB \& L JASCO, Chatsworth, CA, USA) apparatus 2 (paddles) equipped with a Dissoette autosampler (Hanson Research Corporation, Chatsworth, CA, USA) according to the following protocol: a specific amount of MDDS containing $50 \mathrm{mg}$ of BXT was placed in different flasks filled with $100 \mathrm{~mL}$ of dissolution medium. The mixtures were magnetically stirred (with a rotation speed of $50 \mathrm{rpm}$ ), at $37 \pm 0.5^{\circ} \mathrm{C}$; the sampling interval was set at $30 \mathrm{~min}$ during the first hour of the test, and at $60 \mathrm{~min}$ for the next $12 \mathrm{~h}$, respectively. Aliquots $(3 \mathrm{~mL})$ were withdrawn and subjected to HPLC analysis in order to determine the amount of the released BXT. After every sampling, the aliquots were replaced with equal volumes of dissolution medium at $37^{\circ} \mathrm{C}$. The amount of released BXT in the dissolution medium was assessed by the HPLC-DAD method described below.

The chromatographic method applied for the in vitro release tests was developed and validated in-house. The determinations were made on a HPLC Dionex Ultimate ${ }^{\mathrm{TM}}$ 3000 (Thermo Fisher Scientific Inc., USA), equipped with UV-VIS Diode Array Detector and Hypersil GOLD column (Thermo Fisher Scientific Inc., USA), $4.6 \times 150 \mathrm{~mm}$, $5 \mu \mathrm{m}$, and a universal pre-column (Thermo Fisher Scientific Inc., USA). The dosing method was validated for as follows: the mobile phase consisted of $0.1 \%$ trifluoroacetic acid / acetonitrile aqueous solution in a ratio of 20/80 at a flow rate of $1.6 \mathrm{~mL} / \mathrm{min}$; temperature in the column compartment is kept constant at $40{ }^{\circ} \mathrm{C}$; the volume of injected solution is $20 \mu \mathrm{L}$. Chromatograms have been registered at $\lambda=262 \mathrm{~nm}$; linearity is in the range of 0.1 to $1 \mathrm{mg} / \mathrm{mL}$; calibration curve equation, $y=934.49 x+0,986$; the detec- 
tion limit is $0.00822 \mathrm{mg} / \mathrm{mL}$ and the limit of quantification is $0.02491 \mathrm{mg} / \mathrm{mL}$.

\section{6. Characterization}

The degree of ordering for the pure and functionalized MCM-41 samples was determined by Small-Angle $\mathrm{X}$-ray Scattering (SAXS) technique using a Bruker-Nanostar $U$ instrument equipped with a 3-pinhole collimation optics which provides a precisely parallel X-ray beam with virtually no background and high intensity. The scattering intensity was measured as a function of scattering angle in the range $2 \theta=0.5-3.5^{\circ}$.

Textural properties were determined from nitrogen sorption isotherms, registered on a Quantachrome Nova 2200e Surface Area \& Pore Analyzed. Prior to the measurements, all samples have been outgassed in vacuum for $12 \mathrm{~h}$, at room temperature. The specific surface area $\left(\mathrm{S}_{\mathrm{BET}}\right.$, $\mathrm{m}^{2} / \mathrm{g}$ ) was calculated from the linear part of the isotherm applying multipoint $\mathrm{BJH}$ (Brunauer-Emmett-Teller) method. The mean pore diameter $(\mathrm{Dp}, \mathrm{nm})$ was taken from the PSD (pore size distribution), calculated using BHJ (Barrett-Joyner-Halenda) method applied to the adsorption branch of isotherm, as the peak centre. The total pore volume $\left(\mathrm{TPV}, \mathrm{cm}^{3} / \mathrm{g}\right)$ was estimated from the nitrogen adsorbed amount at $\mathrm{P} / \mathrm{P}_{0}=0.95$.

Transmission Electron Microscopy (TEM) investigations were performed using a HT7700 HITACHI microscope operated in high contrast mode at $100 \mathrm{kV}$ accelerating voltage. The samples were prepared by direct deposition of solid gels particles on 300 mesh formvar-coated carbon grids (Ted Pella).

The study on BXT immobilization was followed using an HPLC Dionex Ultimate ${ }^{\mathrm{TM}} 3000$ (Thermo Fisher Scientific Inc., USA).

FTIR spectra were recorded on a Bruker Vertex 70 type FTIR spectrometer. Registered spectra were obtained on $\mathrm{KBr}$ pellets containing prepared samples, in the range of 400 $4000 \mathrm{~cm}^{-1}$ with a resolution of $2 \mathrm{~cm}^{-1}$ at room temperature.

TG analysis was performed using a Diamond Pyris TG-DTA thermobalance (Perkin-Elmer) apparatus under $\mathrm{N}_{2}$ flow. Thermograms were recorded at a heating rate of $10 \mathrm{~K} / \mathrm{min}$, sample mass of about $10 \mathrm{mg}$, temperature interval $40-700^{\circ} \mathrm{C}$.

\section{Results and Discussions}

\section{1. Structural and Morphological Characterization}

Although X-ray diffraction (XRD) is an ideal method to identify the material structure, the nanoparticles are of particular case exhibiting drawbacks as shifting of the diffraction peaks resulting in network parameters modification (compare to the bulk) and peak widening as a result of occasional presence of disordered crystallographic phase. For the structural analysis of the studied samples we considered SAXS (Small Angle X-ray Scattering) technique which is sensitive to the inhomogeneous electronic density. In addition, SAXS results were correlated with those obtained by TEM (Transmission Electron Microscopy). As observed, the Fig. 1 shows SAXS profiles of pure (M) and amino-functionalized $\left(\mathrm{MG}_{\mathrm{x}}\right)$ mesoporous silica samples.

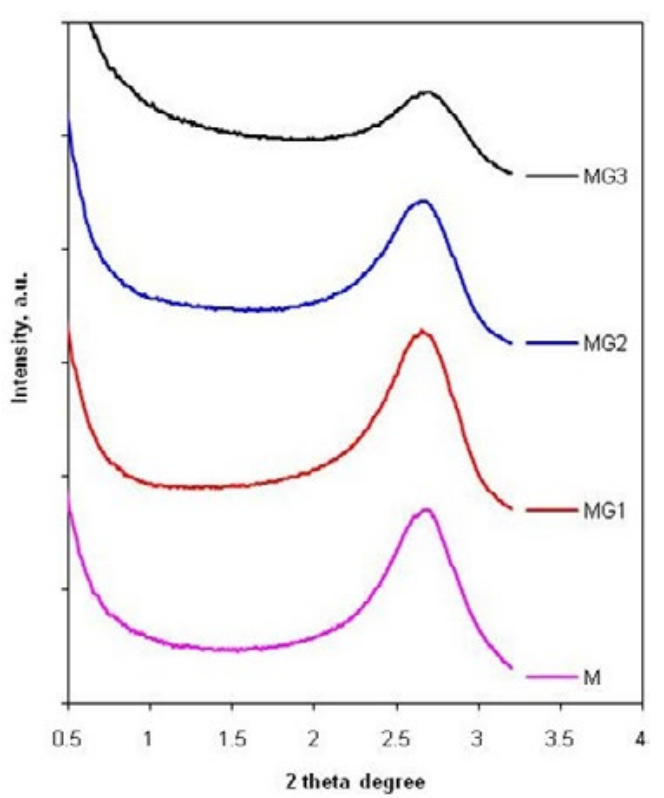

Figure 1. SAXS profiles of the pure (M) and amino-functionalized mesoporous silica $\mathrm{MG}_{\mathrm{x}}$ samples.

As it is observed, the control sample (M) exhibit a clear peak centered at $2 \theta=2.69^{\circ}$, that is characteristic to the typical hexagonal arrangement of the cylindrical channels of mesoporous MCM-41 type silica. When the silica material has been grafted with amino-functionalized groups, we found that the peak intensity decrease with the increase of functionalization degree as a result of organic fragment attachment to the pore walls (Fig.1). The Scherrer equation allowed calculating the interplanar distances as $3.29 \mathrm{~nm}$ for $\mathrm{M}, 3.31 \mathrm{~nm}$ for $\mathrm{MG}_{1}, 3.32$ for $\mathrm{MG}_{2}$, and 3.28 $\mathrm{nm}$ for $\mathrm{MG}_{3}$ samples, respectively.

For the morphology development of the synthesized samples, TEM technique has been involved. Thus, the TEM images obtained are presented in Fig. 2 showing a clear parallelism of the pores arranged concentric in a spherical particle. The medium measured size of the silica particles is about $250 \mathrm{~nm}$. The particle size distribution show the mean particle diameter in the range of $150-300 \mathrm{~nm}$ (Fig.2c); there are only few particles $2 \%$ that have diameter smaller than $100 \mathrm{~nm}$ and $8 \%$ of particles have diameters in the range of $300-400 \mathrm{~nm}$, thus the mesoporous silica nanoparticles being suitable for biomedical applications.

It is found that after the amino-grafting (in the case of $\mathrm{MG}_{1}$ sample, Fig.2b) and BXT-loading (in the case of 


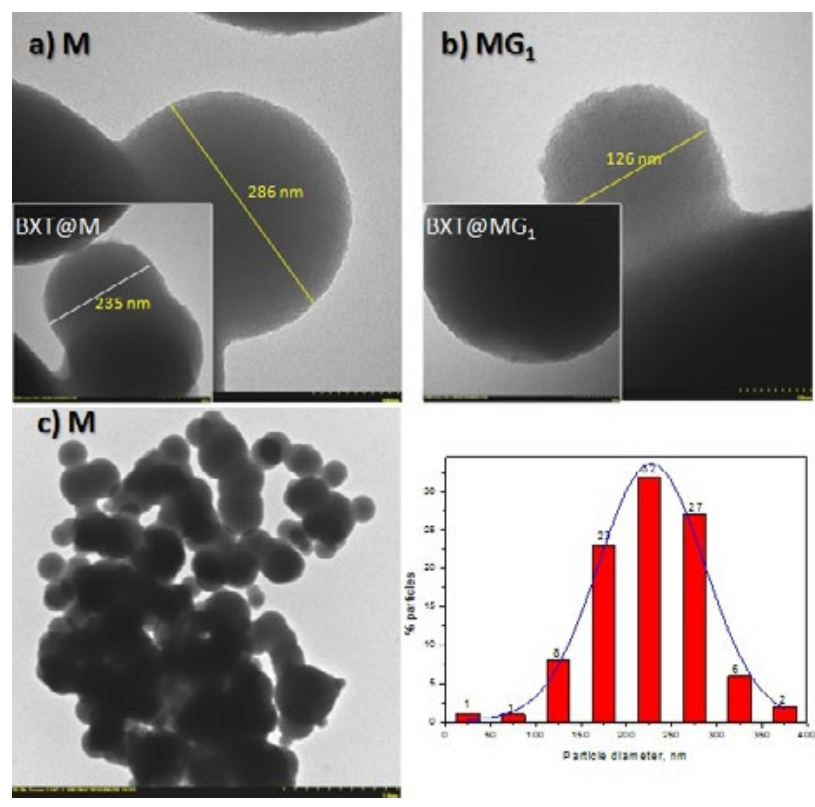

Figure 2. TEM images of: (a) $M$ sample; (b) $M_{1}$ sample; BXT@M sample (a inset); BXT@MG sample (b inset); (c) particle size distribution of M sample.

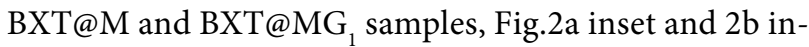
set, respectively) the silica material retains the ordered porous structure, providing its stability during considered processes. Therefore, both SAXS and TEM results show an evident hexagonal ordered pore structure of MCM-41 type silica which is maintained even it has been functionalized and/or loaded with antineoplastic agent.

\section{2. Textural Characterization}

The specific surface area and porosity have a decisive influence on the silica material performance applied in ad-

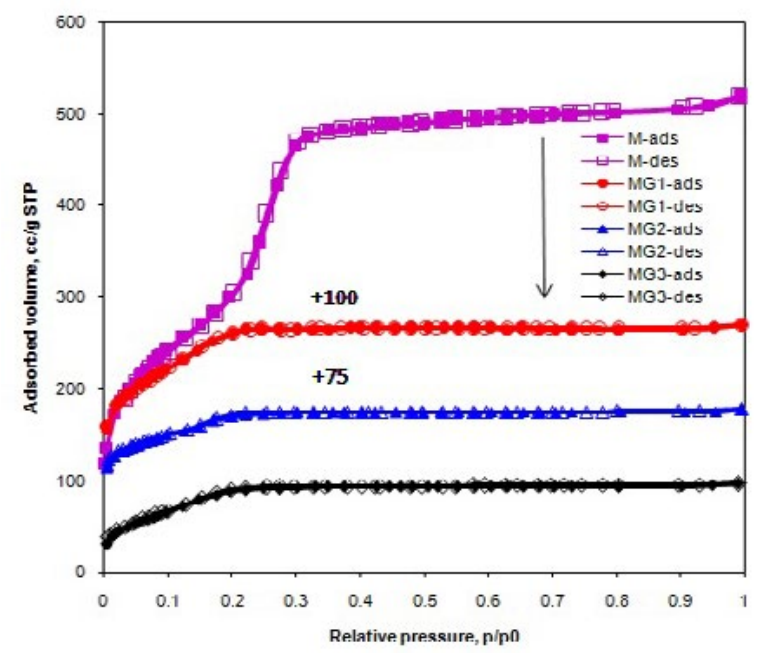

sorption processes, catalysis and not least in preparation of drug delivery systems. In this study it is use the usual nitrogen sorption method for determining the specific surface area and porosity features. The obtained values for the specific surface area, pore volume and diameter are listed in Table 1. According to IUPAC classification, ${ }^{29}$ the starting MCM-41 sample (M), as well as amino-functionalized silica samples $\left(M G_{\mathrm{x}}\right)$ reveals type IV nitrogen adsorption isotherms (Fig. 3 left). These isotherms exhibit the capillary condensation in the range of $\mathrm{P} / \mathrm{P}_{0}=0.2-0.3$ and a very narrow hysteresis loop of type $\mathrm{H} 1$, both features being characteristic to mesoporous materials. The inflection is due to the capillary condensation, and the hysteresis appears in the range of multilayer physisorption being associated with the capillary condensation process in the mesoporous structure. The $\mathrm{H} 1$ hysteresis proves the presence of uniform pores exhibiting a very narrow pore size distribution. The obtained textural characteristics of $\mathrm{M}$ sample $\left(\mathrm{S}_{\mathrm{BET}}=1060 \mathrm{~m}^{2} / \mathrm{g}\right.$; $\mathrm{V}_{\mathrm{p}}=$ $0.790 \mathrm{~cm}^{3} / \mathrm{g} ; \mathrm{D}_{\mathrm{p}}=2.32 \mathrm{~nm}$ ) are in good agreement with the literature. The Fig.3 right (inset) shows the narrow pore size distribution with a single sharp peak of $\mathrm{M}$ silica sample.

The narrow pore size distribution (Fig.3 right), is maintained even after amino-functionalization process mentioning that the pore diameter decreases with increase of functionalization degree (Table I). For amino-functionalized samples, there is a noticeable decrease in the value of all texture parameters $\left(\mathrm{S}_{\mathrm{BET}}, \mathrm{V}_{\mathrm{p}}, \mathrm{D}_{\mathrm{p}}\right)$, explained by bonding a number of organic fragments on the inner surface of the pores. Textural parameters diminishing is a function of functionalization degree (expressed by a percentage content of aminopropyl groups, Table I), being inversely proportional to it (once increased the functionalization degree, the textural parameters are diminished).

In the case of BXT@MG systems (the isotherms are not shown here) a different behavior was observed dependent on the functionalization degree. Thus nitrogen sorp-

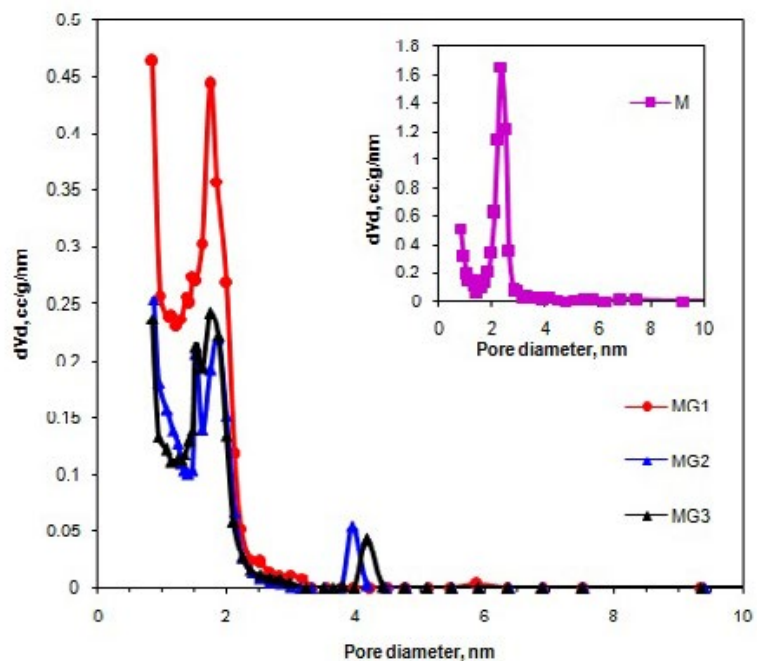

Figure 3. Nitrogen adsorption isotherms for pure and amino-functionalized silica samples $\mathrm{MG}_{\mathrm{x}}$ (left); corresponding pore size distributions (right). 
tion isotherm for BXT@MG system kept the same type I, which at high relative pressures exhibit a small $\mathrm{H} 1$ type hysteresis loop associated with the capillary condensation process in the secondary porosity (interparticle pores). Simultaneously have been observed a drastically decrease of the specific surface area which is due to the occupation of an important volume fraction of the pores with BXT molecules, and the pore sizes are in the range of micropores $(<2 \mathrm{~nm})$ (Table 1). At the same time, the nitrogen adsorption isotherms for BXT@MG and BXT@MG $\mathrm{MG}_{3}$ systems show the absence of porosity (the isotherms being of type II which are characteristic to non-porous materials) suggesting the pore filling or blocking.

\section{3. Drug Loading}

Kinetic curves describing the adsorption process of BXT molecules on $\mathrm{MG}_{\mathrm{x}}$ series samples, expressed by a decrease of the drug concentration in the solution are shown in Fig. 4.

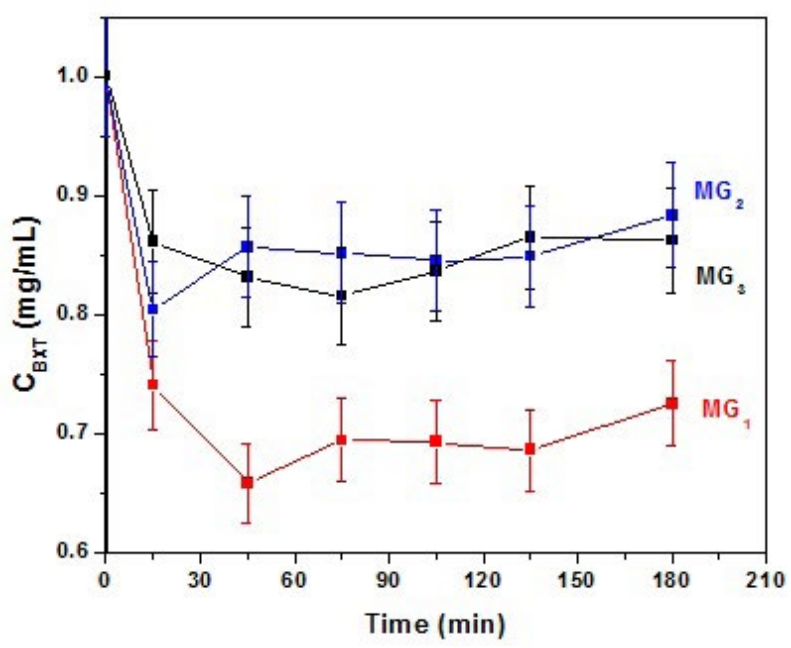

Figure 4. Adsorption kinetics of $\mathrm{BXT}$ molecules on $\mathrm{MG}_{\mathrm{x}}$ matrices.

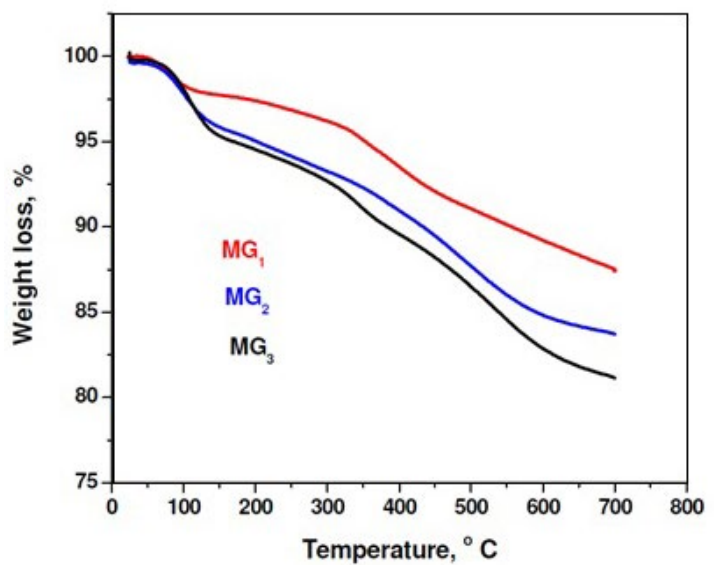

It is found that the diffusion process of BXT molecules through mesoporous silica structure and their adsorption on the active centers is relative fast, reaching the equilibrium in only $3 \mathrm{~h}$.

The amount of aminopropyl groups calculated from thermogravimetric analysis (TG) on amino-functionalized mesoporous silica samples have the following values: $10.26 \mathrm{wt} \%$ for $M G_{1}$ sample, $12.14 \mathrm{wt} \%$ for $\mathrm{MG}_{2}$ sample, and $14.18 \mathrm{wt} \%$ for $\mathrm{MG}_{3}$ sample (Table I).

The Figure 4 reveals a maximum BXT loading for $\mathrm{MG}_{1}$ sample which has a minimum functionalization degree compare to the other $\mathrm{MG}_{\mathrm{x}}$ samples. The BXT loading varies inversely with the functionalization degree according to the following series: $\mathrm{MG}_{1}>\mathrm{MG}_{2}>\mathrm{MG}_{3}$.

This result shows that the optimum of the functionalization degree in the study conditions is of $10.26 \mathrm{wt} \%$ owned to $\mathrm{MG}_{1}$ sample. At $12.14 \mathrm{wt} \%$, and $14.18 \mathrm{wt} \%$, respectively of functionalization degree, the low loading lev$\mathrm{el}$ is due to the large number of organic fraction (aminopropyl groups) grafted on the pore walls which produce the filling of a large fraction of the pore volume and thus diffusion hindrances, either by pore blocking at the entrance or by the formation of pillars inside pores. The retained BXT quantity (228.6 mg/g for $\mathrm{MG}_{1}$ sample; 180.5 $\mathrm{mg} / \mathrm{g}$ for $\mathrm{MG}_{2}$ sample; and $165.4 \mathrm{mg} / \mathrm{g}$ for $\mathrm{MG}_{3}$ sample) varies inversely to the functionalization degree, the best loading being exhibited by $\mathrm{MG}_{1}$ sample.

Because BXT molecules are retained involving electrostatic forces, the crystallization on the active centers is blocked, leading to enhanced drug solubility, bioavailability respectively. Thus, due to the unique structure of the amino-functionalized mesoporous silica, the textural properties and internal surface chemistry could be considered as highly efficient carrier for BXT molecules.

\section{4. Thermogravimetric Analysis}

The amount of amino-groups attached to the mesoporous silica $\mathrm{MG}_{\mathrm{x}}$ surface was determined by thermograv-

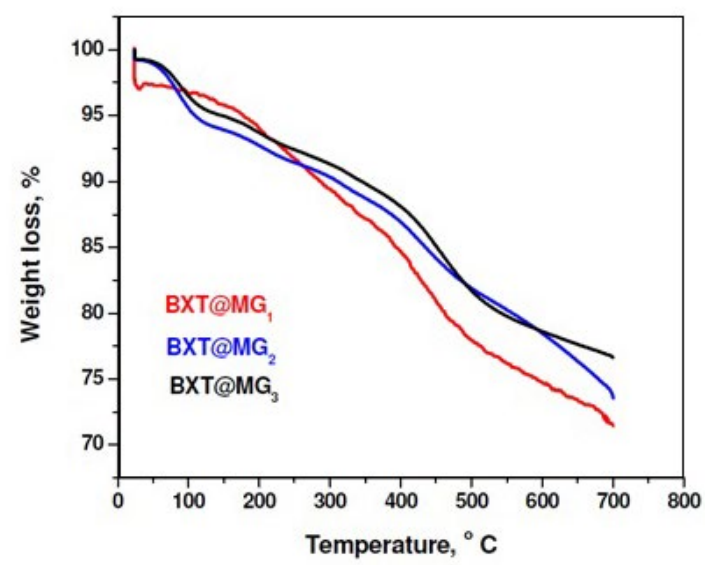

Figure 5. Thermogravimetric curves for functionalized silica samples $\left(\mathrm{MG}_{1}, \mathrm{MG}_{2}, \mathrm{MG}_{3}\right)$ and bexarotene loaded samples $\left(\mathrm{BXT}_{\mathrm{N}} \mathrm{MG} \mathrm{G}_{1}, \mathrm{BXT} @ \mathrm{MG} \mathrm{G}_{2}\right.$, BXT@MG $)$. 
imetric analysis. This method is sensitive to the total amount of the organic functions present on the mesoporous silica surface. The obtained thermogravimetric curves are presented in Figure 5a.

As observed, all samples show a mass loss at low temperatures (around $150{ }^{\circ} \mathrm{C}$ ) which is due to the water molecules desorption. The mass loss at higher temperatures than $150^{\circ} \mathrm{C}$ is due to the decomposition of aminopropyl groups anchored on the mesoporous silica surface, showing a successful surface functionalization (Table 1). The functionalization degree varies in the series $\mathrm{MG}_{1}<\mathrm{MG}_{2}<\mathrm{MG}_{3}$.

At temperatures above $150{ }^{\circ} \mathrm{C}$, the $\mathrm{BXT} @ \mathrm{MG}_{\mathrm{x}}$ systems show higher mass loss compare to only aminofunctionalized samples due to decomposition of aminopropyl groups anchored on the silica surface, as well as bexarotene molecules desorption. Thus, the BXT@MG system shows a BXT loading of 14.04 wt\%, 8.208 wt\% for BXT@MG sys- $_{2}$ tem, and $4.117 \mathrm{wt} \%$ for BXT@MG 3 system (Table 1). These results indicate that the BXT loading is in good agreement with the functionalization degree. The functionalization degree of $10.26 \mathrm{wt} \%$ which is characteristic to BXT@MG $\mathrm{M}_{1}$ system can be considered to be an optimum in the present study conditions, suggesting the induction of a sufficient powerful electrostatic field for retention of BXT molecules. As well, the fraction of the pore volume occupied by the aminopropyl groups is small enough not to hinder BXT molecules hosting. The increase of the functionalization degree (the case of BXT@MG $\mathrm{MG}_{2}$ and BXT@MG systems) lead to a decrease of bexarotene loaded as a result of diminishing the available pore volume for BXT molecules. The loading level with BXT in the case of all $\mathrm{MG}_{\mathrm{x}}$ samples show that the silica pores have not been blocked by the aminopropyl groups, functionalization being beneficial.

\section{5. FTIR Analysis}

Mesoporous silica sample $\mathrm{M}$, amino-functionalized $\left(\mathrm{MG}_{\mathrm{x}}\right)$, as well modified drug delivery systems, (BXT@M

a)

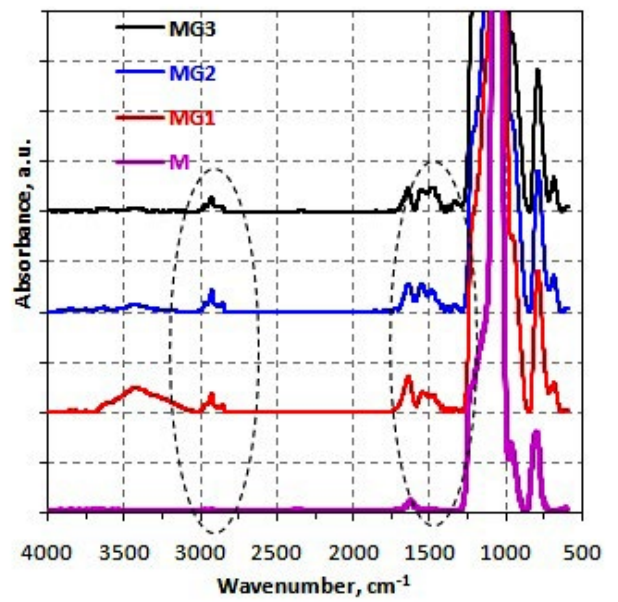

and BXT@MG ), were analyzed by FTIR spectroscopy with the aim to highlight the presence of amino groups and the anticancer agent on the silica surface.

It is well known that an IR spectrum is composed of two distinct regions: the fingerprint region in the range of $1450-500 \mathrm{~cm}^{-1}$ and the functional groups range of $4000-$ $1450 \mathrm{~cm}^{-1}$. The fingerprint region contains, usually a series of absorption bands due to all vibration modes that occur inside molecule. It is difficult to assign individual absorption in this region but their apparition is very important because is unique for each compound being used to identify a compound. In the region of functional groups are less absorption bands being relatively easy to identify their nature.

The corresponding spectra for the functionalized silica hosts $\left(M G_{x}\right)$, compare to pure silica matrix $(M)$, are presented in Fig. 6 a.

Both, in the fingerprint region and amino-functional groups are observed modifications as the result of the functionalization process. In the fingerprint region the spectra are similar, the absorption bands being localized at $1060 \mathrm{~cm}^{-1}$ and $806 \mathrm{~cm}^{-1}$ are assigned to symmetric and asymmetric stretching vibrations of $\mathrm{Si}-\mathrm{O}-\mathrm{Si}$ which are dominant with an increase intensity and a small shift toward low frequency, characterizing the spectra of $M_{\mathrm{x}}$ samples, as a result of the influences of vibrations that occur in APTES molecule.

The main differences between spectra of $M$ sample and amino-functionalized silica samples $\left(\mathrm{MG}_{\mathrm{x}}\right)$ are found in the range of functional groups and consist of: (i) the presence of absorption bands centered at $2924 \mathrm{~cm}^{-1}$ and $2855 \mathrm{~cm}^{-1}$ assigned to the stretching vibrations of $(\mathrm{C}-\mathrm{H})$ (typical bands for alkyl C-H stretching frequencies); (ii) the band at about $1643 \mathrm{~cm}^{-1}$ might be attributed to asymmetric deformation of protonated amine groups $-\mathrm{NH}_{3}^{+} ; 30$ (iii) the absorption band at $1551 \mathrm{~cm}^{-1}$ is assigned to symmetric bending vibration of $\mathrm{NH}_{2}$ or $\mathrm{NH}_{3}^{+}$groups. All these supplementary absorptions present in the FTIR spectra of MGx samples show a success functionalization process.

b)

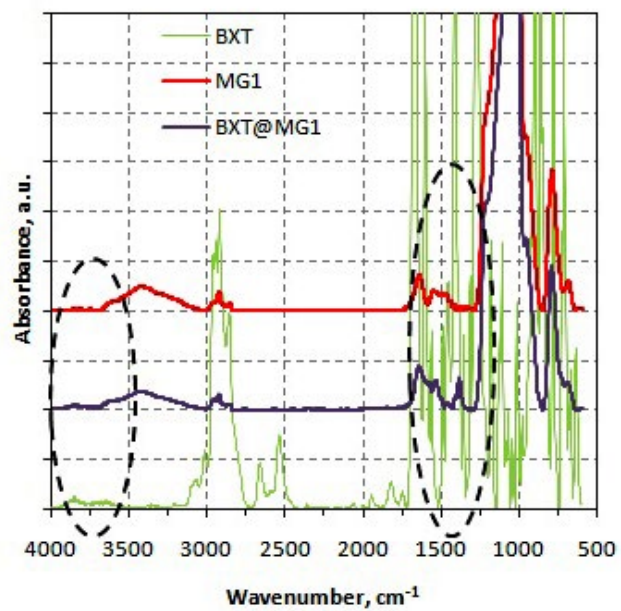

Figure 6. a) FTIR spectra for amino-functionalized $\mathrm{MG}_{\mathrm{x}}$ samples compare to pure silica M sample; b) FTIR spectra for BXT@MG $\mathrm{B}_{1}$ system compare to $\mathrm{MG}_{1}$ and BXT samples. 
Table 1. Textural and thermogravimetric parameters of the aminofunctionalized $\mathrm{MG}_{\mathrm{x}}$ samples and $B X T @ M G_{x}$ systems.

\begin{tabular}{|c|c|c|c|c|c|c|}
\hline Sample & $\begin{array}{l}\mathrm{S}_{\mathrm{BET}} \\
\mathbf{m}^{2} / \mathrm{g}\end{array}$ & $\begin{array}{c}\mathrm{V}_{\mathrm{p}} \\
\mathrm{m}^{3} / \mathrm{g}\end{array}$ & $\begin{array}{c}\mathrm{D}_{\mathrm{p}} \\
\mathbf{n m}\end{array}$ & $\begin{array}{c}\text { Water content, } \\
\text { wt } \%\end{array}$ & $\begin{array}{c}\text { Aminopropil group } \\
\text { content, wt } \%\end{array}$ & $\begin{array}{l}\text { BXT loading, } \\
\text { wt } \%\end{array}$ \\
\hline M & 1060 & 0.790 & 2.32 & - & - & - \\
\hline $\mathrm{MG}_{1}$ & 608 & 0.256 & 1.73 & 2.26 & 10.26 & - \\
\hline $\mathrm{MG}_{2}$ & 303 & 0.148 & 1.62 & 4.14 & 12.14 & - \\
\hline $\mathrm{MG}_{3}$ & 288 & 0.147 & 1.52 & 4.67 & 14.18 & - \\
\hline BXT@M & 802 & 0.443 & 2.21 & - & - & - \\
\hline BXT@MG & 53 & 0.039 & 1.33 & 4.23 & 10.26 & 14.04 \\
\hline BXT@MG & 22 & 0.027 & - & 6.09 & 12.14 & 8.208 \\
\hline BXT@MG & - & - & - & 5.05 & 14.18 & 4.117 \\
\hline
\end{tabular}

In the case of BXT, because the literature does not report so many and incomplete data, the comparative study with the data obtained in this work was almost impossible. Were used informations reported by the International Agency for Research on Cancer (World Health Organization), ${ }^{31}$ where are indicated the following band to be characteristic to BXT compound: $2959 \mathrm{~cm}^{-1} ; 1677 \mathrm{~cm}^{-1}$; $1278 \mathrm{~cm}^{-1}$.

The characteristic FTIR spectra of the BXT@MG system are presented in Fig.6b compare to $\mathrm{MG}_{1}$ and $\mathrm{BXT}$ samples. It was found that each spectrum characterizing MDDS systems exhibit modifications in the region of $3900-3600 \mathrm{~cm}^{-1}$, and $1600-1300 \mathrm{~cm}^{-1}$ respectively (Fig. $6 \mathrm{~b}$ ) which are due to the presence of BXT molecules.

The obtained thermogravimetric and FTIR results show the amino-modification of the silica surface and BXT loading have been reach successful.

\section{6. Analysis of in vitro Drug Release Kinetics}

In order to predict and correlate the behavior of the in vitro BXT release from the MDDSs studied, a suitable

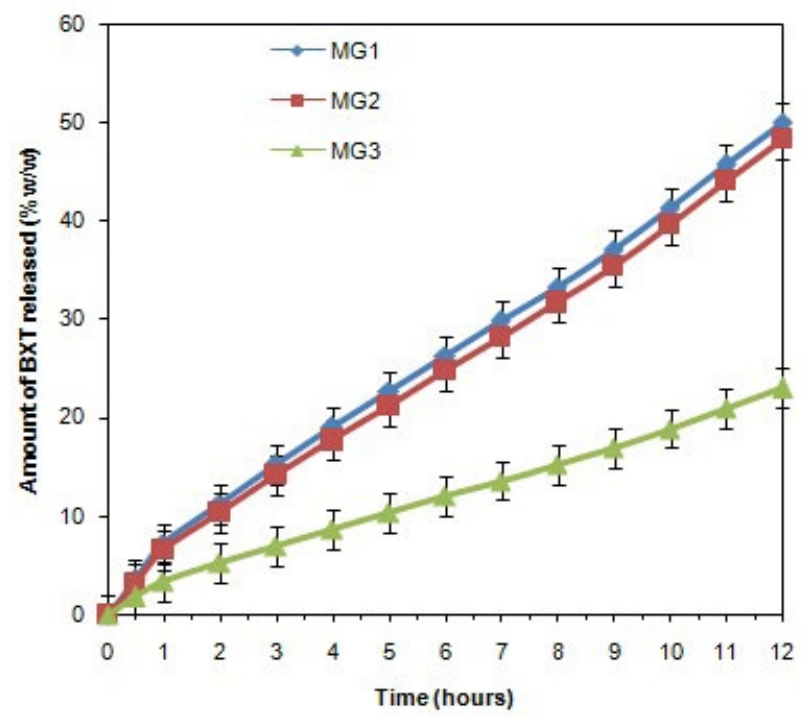

Figure 7. In vitro dissolution release of BXT from BXT@MG $\mathrm{G}_{\mathrm{x}}$ systems. mathematical model was used. Thus, the experimental data obtained from the in vitro dissolution tests of BXT from MDDSs were investigated using four predictable models: zero-order and first-order kinetics, Higuchi, and Korsmeyer-Peppas models. ${ }^{32,33}$ The simulation analysis, plotting and data fitting have been performed using Matlab 7.1 software. The Akaike Information Criterion (AIC) and the correlation coefficient $\mathrm{R}^{2}$ were the criteria for selecting the model that most dependably describes the release profile of each formula. In a reliable prediction mod$\mathrm{el}$, the value of $\mathrm{R}^{2}$ is as close to 1 as possible, and AIC has the lowest values possible. ${ }^{34}$

In vitro dissolution tests gave the results that highlight a prolonged release of BXT from the studied systems during 12 h. BXT@MG $\mathrm{MG}_{1}$ and BXT@MG $\mathrm{M}_{2}$ systems were conducted to a $50 \%$ release of loaded BXT, while BXT@MG $\mathrm{MG}_{3 c}$ system releases only 22.97\% (Fig. 7).

$$
\begin{aligned}
& (\text { Cumulative release }(\%)= \\
& \left.=\frac{\text { Amount of BXT released to solution }}{\text { Amount of BXT placed in MDDS }} * 100\right)
\end{aligned}
$$

These values are due to the presence of aminopropyl groups on the pore walls which reduce the liquid medium influx and delay the drug release because of the steric hindrance.

The obtained kinetics results for BXT release were fitted to mathematic models and are listed in Table 2. Correlating the quantity of released BXT with functionalization degree and porosity features of the amino-functionalized hosts and MDDSs systems we can conclude that in the case of BXT@MG $\mathrm{M}_{3}$ system the physical interaction between BXT molecules and grafted aminopropyl groups on the silica pore walls are stronger and diffusion restrictions are more important due to the large number of aminopropyl groups.

Kinetics analysis of BXT release by fitting selected mathematical models conducted to results presented in Table 2.

The data presented in Table 2 show a very good description of in vitro release rate of bexarotene from BXT@MG $\mathrm{M}_{1}$ and BXT@MG $\mathrm{M}_{2}$ systems by the first order kinetic model given by the following equation: 


$$
\log C=\log C_{0}-\frac{K_{t}}{2.303}
$$

Where, $\mathrm{C}_{0}$ - initial concentration of drug; $\mathrm{K}=$ first order constant; $\mathrm{t}=$ time. $^{35}$

The $\mathrm{R}^{2}$ values obtained for BXT@MG $\mathrm{M}_{1}$ and BXT@ $\mathrm{MG}_{2}$ systems were close to 0.990 (namely: 0.9816 for BXT@MG and 0.9821 for BXT@MG ${ }_{2}$, respectively). This result show that BXT release from such systems occur through a Fickian diffusion mechanism (Fick's first law) which is associated with concentration gradient, diffusion distance.

Table 2. Results of curve fitting of the in vitro BXT release profile from DDS silica based.

\begin{tabular}{|c|c|c|c|c|}
\hline \multirow{2}{*}{$\begin{array}{l}\text { Kinetic } \\
\text { model }\end{array}$} & \multicolumn{2}{|l|}{ Model } & \multicolumn{2}{|c|}{ MDDS System } \\
\hline & Coefficients & $\mathrm{MG}_{1}$ & $\mathrm{MG}_{2}$ & $\mathrm{MG}_{3}$ \\
\hline \multirow[t]{3}{*}{ Zero-order } & $\mathrm{K}_{0}$ & 3,8194 & 3.6649 & 1.7505 \\
\hline & $\mathbf{R}^{0}$ & 0.9136 & 0.9237 & 0.9113 \\
\hline & AIC & 49.4720 & 46.7538 & 26.3153 \\
\hline \multirow[t]{3}{*}{ First-order } & $\mathrm{K}_{1}$ & 0.0503 & 0.0477 & 0.0195 \\
\hline & $\mathbf{R}^{2}$ & 0.9816 & 0.9821 & 0.9489 \\
\hline & AIC & 26.2972 & 25.0074 & 18.0581 \\
\hline \multirow[t]{3}{*}{ Higuchi } & $\mathbf{K}_{\mathrm{H}}$ & 12.1607 & 11.6362 & 5.5762 \\
\hline & $\mathbf{R}^{\mathbf{2}}$ & 0.9277 & 0.9187 & 0.9292 \\
\hline & AIC & 46.7955 & 47.7164 & 22.9385 \\
\hline Korsmeyer- & $\mathbf{n}$ & 0.8 & 0.8 & 0.7 \\
\hline \multirow[t]{3}{*}{ Peppas } & $\mathbf{K}_{\mathbf{p}}$ & 6.2042 & 5.9472 & 2.8438 \\
\hline & $\mathbf{R}^{2}$ & 0.9723 & 0.9740 & 0.9783 \\
\hline & AIC & 34.4399 & 32.6389 & 7.1675 \\
\hline
\end{tabular}

In the case of BXT@MG 3 system, the release rate of $\mathrm{BXT}$ is best described by Korsmeyer-Peppas model given by the following equation:

$$
\frac{M_{t}}{M_{\infty}}=K_{t}^{n}
$$

Where: $M_{t}$ and $M_{\infty}$ denote the cumulative mass of drug released at time $\mathbf{t}$ and at infinite time, respectively;

$\mathrm{K}$ - is a kinetic constant characteristic of the drug-carrier system;

$\mathrm{n}$ - is an exponent (release index), which gives the information about the release mechanism of drug.

To find out the mechanism of drug release (exponent $n$ - release index), first $60 \%$ of the drug release data were fitted in Korsmeyer-Peppas model..$^{36}$

The index release value, $\mathrm{n}=0.7$, for $\mathrm{BXT} @ \mathrm{MG}_{3}$ system is in the range $0.45<\mathrm{n}<0.89$ indicating a BXT release through an anomalous transport by diffusion processes (a non Fickian or anomalous diffusion is present). ${ }^{37}$
This result highlights the fact that the amino-functionalization degree of mesoporous silica MCM-41 plays a very important role in the loading and release processes of guest drug molecules. Therefore, the differences in physicochemical properties such the surface area and porosity determine the drug release mechanism via influence of the accessibility and mobility of drug molecules inside the pores of silica material and then their release behavior.

\section{Conclusions}

Mesoporous silica MCM-41 type have been synthesized and modified by post-synthetic grafting method with various level of amino-functionalization, loaded with specific antineoplastic drug specific for treatment of cutaneous T-cell lymphoma and investigated as carrier in MDDSs systems. To the best of our knowledge, it is the first time studied such MDDS systems, BXT@MCM-41 mesoporous pure or amino-functionalized silica type.

The structural, textural and morphological characteristics evidenced the highly ordered structure degree of MCM-41, hexagonal arrangement of pores, spherical morphology of nanoparticles, specific surface area, pore size distribution in good agreement with the data reported elsewhere. Amino-functionalization by post-synthetic grafting diminished textural characteristics (specific surface area, pore diameter and volume) closely related to the functionalization degree. While occupying a certain fraction of the pore volume by aminopropyl groups, was modified the nitrogen adsorption isotherm type from type IV to type I, characterizing microporous materials.

TG and FTIR results showed the amino-modification of the silica surface and BXT loading have been reaching successful. Loading of amino-functionalized mesoporous silica with antineoplastic agent specific for cutaneous T-cell lymphoma, as in vitro release it was shown to be dependent of amino-functionalization degree thus illustrating truth fullness of the aim of the present study.

The control of the drug release process through amino-functionalization was demonstrated by release rate fitting (kinetics curves) using four mathematical models considered to be the most appropriate. Is has been demonstrated the prolonged release of the drug from the studied modified drug delivery systems is due to the unique structural properties of mesoporous silica MCM-41 and to the controlled modification of the surface chemistry and textural features through amino-functionalization.

In the BXT@MG type systems, the bexarotene molecules are adsorbed on the active centers (aminopropyl groups) in non-crystalline state proving the major role of amino-functionalized MCM-41 silica for the solubility enhancing of BXT in water (enhancing dissolution of poorly-water soluble bexarotene) and by this of the drug bioavailability. 
The results of the present study show that due to the unique structure, textural properties and internal surface chemistry of the amino-functionalized mesoporous silica, MCM-41, this is high efficiently carrier for the studied antineoplastic agent, and the obtained MDDSs systems are promising in biomedical applications, especially in controlled DDSs for obtaining topical formulations.

\section{Acknowledgments}

This work was performed through the Partnerships in priority areas program - PN II, developed with support of MEN - UEFISCDI, project PNII-PT-PCCA-2013-4-2024 (TOP-CTCL).

\section{References}

1. Z. Lin, W. Gao, H. Hu, K.Ma, B. He, W. Dai, X. Wang, J. Wang, X. Zhang, Q. Zhang, J Control Release. 2014, 174, 161-70. DOI:10.1016/j.jconrel.2013.10.026

2. C. Loira-Pastoriza, K. Todoroff, R. Vanbever, Adv. Drug Deliv. Rev. 2014, 75, 81-91. DOI:10.1016/j.addr.2014.05.017

3. M. D. Chavanpatil, P. Jain, S. Chaudhari, R. Shear, P. R. Vavia, Int. J. Pharm. 2006, 316, 86-92.

DOI:10.1016/j.ijpharm.2006.02.038

4. C. W. Vendruscolo, I.F . Andreazza, M. S. Ganter, C. Ferrero, T. M. B. Bresolin, Int. J. Pharm. 2005, 296, 1-11.

DOI:10.1016/j.ijpharm.2005.02.007

5. M. Vallet-Regi, A. Rámila, R. P. del Real, J. Pérez-Pariente, Chem. Mater. 2001, 13, 308-311.

DOI:10.1021/cm0011559

6. J. Andersson, J. Rosenholm, S. Areva, M. Linden, Chem $\mathrm{Ma}$ ter. 2004, 16, 4160-4167. DOI:10.1021/cm0401490

7. W. Zeng, X. F. Qian, Y. B. Zhang, J. Yin, Z. K. Zhu, Mat. Res. Bull. 2005, 40/5, 766-772.

DOI:10.1016/j.materresbull.2005.02.011

8. A. Datt, I. El-Maazawi, S. C. Larsen, J. Phys. Chem. C. 2012, 116(34), 18358-18366. DOI:10.1021/jp3063959

9. D. Halamova, V. Zelenak, J. Incl. Phenom. Macrocycl. Chem. 2012, 72, 15-23. DOI:10.1007/s10847-011-9990-x

10. G. Q. Silveira, R. S. da Silva, L. P. Franco, M. D. Vargas, C. M. Ronconi, Micropor. Mesopor. Mat. 2015, 206, 226-233.

DOI:10.1016/j.micromeso.2014.12.026

11. F.Qu, G. Zhu, S. Huang, S. Li, S. Qiu, Chemphyschem. 2006, 7(2), 400-406. DOI:10.1002/cphc.200500294

12. S. Wang, Micropor. Mesopor. Mat. 2009, 117 /1-2, 1-9. DOI:10.1016/j.micromeso.2008.07.002

13. Ș. Gunaydin, A. Yilmaz, Turk. J. Chem. 2015, 39, 317-333. DOI:10.3906/kim-1409-56

14. V. Ambrogi, L. Perioli, C. Pagano, F. Marmottini, M. Moretti, F. Mizzi, C. Rossi, J. Pharm. Sciences. 2010, 99, 4738-4745. DOI:10.1002/jps.22183

15. Q. Tanga, Y. Xu, D. Wu, Y. Sun, J. Solid State Chemistry. 2006, 179, 1513-1520. DOI:10.1016/j.jssc.2006.02.004
16. M. Popova, A. Szegedi, K. Yoncheva, S. Konstantinov, G.P. Petrova, H. A. Aleksandrov, G. N. Vayssilov, P. Shestakova, Micropor.Mesopor. Mat. 2014, 198, 247-255.

DOI:10.1016/j.micromeso.2014.07.044

17. B. Koneru, Y. Shi, Y-C. Wang, S. H. Chavala, M. L. Miller, B. Holbert, M. Conson, A. Ni, A. J. Di Pasqua, Molecules 2015, 20, 19690-19698. DOI:10.3390/molecules201119650

18. M. Vallet-Regí, F. Balasa, M. Colilla, M. Manzano, Solid State Sci. 2007, 9, 768-776.

DOI:10.1016/j.solidstatesciences.2007.03.026

19. L. Ochiuz, M. C. Luca, I. Stoleriu, M. Moscalu, D. Timofte, G. Tantaru, A. Stefanache, Farmacia, 2016, 64, 131-134.

20. A. Bolouki, L. Rashidi, E. Vasheghani-Farahani, Z. Piravi-Vanak, Int. J. Nanosci. Nanotechnol, 2015, 11(3), 139-146.

21. R. Kotcherlakota, A. K. Barui, S. Prashar, M. Fajardo, D. Briones, A. Rodríguez-Diéguez, C. R. Patra, S. Gómez-Ruiz, Biomater Sci. 2016, 4(3), 448-459.

DOI:10.1039/C5BM00552C

22. F. Porta, G. E. Lamers, J. Morrhayim, A. Chatzopoulou, M. Schaaf, H. den Dulk, C. Bachendorf, J. I. Zink, Adv. Healthcare Mater. 2013, 2, 281-286. DOI:10.1002/adhm.201200176

23. A. L. Doadrio, A. J. Salinas, J. M. Sánchez-Montero, M. Vallet-Regí, Curr Pharm Des. 2015, 21, 6189-6213. DOI:10.2174/1381612822666151106121419

24. A. M. Tomoiaga, B. I. Cioroiu, V. Nica, A. Vasile, Colloids Surf B: Biointerfaces. 2013, 111, 52-59. DOI:10.1016/j.colsurfb.2013.05.019

25. A. M. Tomoiaga, L. Ochiuz, A. Vasile, J. Nanotech. Diagn. Treat. 2013, 1, 26-35. DOI:10.12974/2311-8792.2013.01.01.4

26. B. D. Smith, L. D. Wilson, Curr. Probl. Cancer. 2008, 32, 4387. DOI:10.1016/j.currproblcancer.2007.12.002

27. L. Chen, Y. Wang, J. Zhang, L. Hao, H. Guo, H. Lou, D. Zhang, Eur J Pharm Biopharm. 2014, 87, 160-169. DOI:10.1016/j.ejpb.2013.12.005

28. R. P. Gogineni, Rapid liquid chromatography UV detection method development and validation of multiclass drugs in active pharmaceutical ingredients and pharmaceutical dosage forms and applicability to biological matrices. $\mathrm{PhD}$ thesis (2014), Acharya Nagarjuna University. Available at: http:// hdl.handle.net/10603/31065, Accessed: 11 August 2016.

29. M. Thommes, K. Kaneko, A. V. Neimark, J. P. Olivier, F. Rodriguez-Reinoso, J. Rouquerol, K.S.W. Sing, Pure Appl. Chem. 2015, 19 pages.

30. J. Kim, P. Seidler, C. Fill, L.S. Wan, Surf Sci. 2008, 602, 33233330. DOI:10.1016/j.susc.2008.09.001

31. IARC Handbooks of Cancer Prevention, p 317 - 324.

32. N. Ahuja, P. K. Om, B. Singh, Eur. J. Pharm. and biopharm. 2007, 65, 26-38. DOI:10.1016/j.ejpb.2006.07.007

33. L. Ochiuz, C. Grigoras, M. Popa, I. Stoleriu, C. Munteanu, D. Timofte, L. Profire, A.G. Grigoras, Molecules. 2016, 21(7), 858-874. DOI:10.3390/molecules21070858

34. M. C. Gohel, K. G. Sarvaiya, A. R. Shah, B. K. Brahmbhatt, Indian J. Pharm. Sci. 2009, 71, 142-144. DOI: $10.4103 / 0250-474 X .54281$

35. K. H. Ramteke, Sch. Acad. J. Pharm. 2014, 3(5), 388-396. 
36. R. W. Korsmeyer, R. Gurny, E. Doelker, P. Buri, N. A. Peppas,

37. N. A. Peppas, Pharm Acta Helv. 1985, 60, 110-111.

Int. J. Pharm. 1983, 15, 25-35.

DOI:10.1016/0378-5173(83)90064-9

\section{Povzetek}

V pispevku poročamo o prvi uporabi MCM-41 mezoporoznega silicijevega dioksida kot zelo učinkovitega nosilca za beksaroten, antineoplastičnega zdravila namenjenega zdravljenju bolnikov s kožnim T-celičnim limfomom (CTCL). Beksaroten je zelo strupen in slabo topen v vodi, z nizko biološko uporabnostjo v običajnih farmacevtskih oblikah. Podani so rezultati o absorpciji beksarotena na amino-funkcionalizirane nosilce silicijevega dioksida $\mathrm{z}$ različnimi stopnjami funkcionalizacije ob upoštevanju vseh strukturnih značilnosti tako nosilca kot tudi lastnosti molekul zdravilne učinkovine. Dobljeni rezultati so pokazali uspešno vezavo beksarotena na amino-funkcionaliziran silicijev dioksid MCM-41. Molekule beksarotena se adsorbirajo na aktivnih centrih v nekristalnični fazi, kar nakazuje na pomembno vlogo amino kislinskega funkcionaliziranja nosilca na topnost zdravilne učinkovine in izboljšanje biološke uporabnosti. In vitro testi raztapljanja so pokazali podaljšano sproščanje beksarotena v 12 urah in $50 \%$ sproščanje vezanih aktivnih molekul. V raziskavi smo dokazali, da je podaljšano sproščanje učinkovine posledica prisotnosti aminopropilnih skupin na stenah silicijevih por. 